\title{
High BCAR1 expression is associated with early PSA recurrence in ERG negative prostate cancer
}

\author{
Asmus Heumann ${ }^{1 \dagger}$, Nina Heinemann ${ }^{1 \dagger}$, Claudia Hube-Magg ${ }^{1}$, Dagmar S. Lang ${ }^{1}$, Katharina Grupp², Martina Kluth, \\ Sarah Minner', Christina Möller-Koop ${ }^{1}$, Markus Graefen ${ }^{3}$, Hans Heinzer ${ }^{3}$, Maria Christina Tsourlakis ${ }^{1}$, Waldemar Wilczak', \\ Corinna Wittmer', Frank Jacobsen ${ }^{1}$, Hartwig Huland ${ }^{3}$, Ronald Simon ${ }^{1 *} \mathbb{D}$, Thorsten Schlomm ${ }^{3,4}$, Guido Sauter ${ }^{1}$, \\ Stefan Steurer ${ }^{1}$, Patrick Lebok ${ }^{1}$ and Andrea Hinsch ${ }^{1}$
}

\begin{abstract}
Background: Breast cancer anti-estrogen resistance 1 (BCAR1/p130cas) is a hub for diverse oncogenic signaling cascades and promotes tumor development and progression.

Methods: To understand the effect of BCAR1 in prostate cancer, we analyzed its expression on more than 11,000 prostate cancer samples. BCAR1 expression levels were compared with clinical characteristics, PSA recurrence, molecular subtype defined by ERG status and 3p, 5q, 6q and PTEN deletion.

Results: BCAR1 staining was barely detectable in normal prostate glands but seen in $77.6 \%$ of 9472 interpretable cancers, including strong expression in 38.5\%, moderate in 23.2\% and weak in 15.9\% of cases. BCAR1 up regulation was associated with positive ERG status $(p<0.0001)$, high Gleason score $(p<0.0001)$, advanced pathological tumor stage $(p=0.0082)$, lower preoperative PSA level $(p<0.0001)$, increased cell proliferation $(p<0.0001)$, early PSA recurrence $(p=0.0008)$, and predicted prognosis independently from clinico-pathological parameters available at the time of the initial biopsy. However, subset analyses revealed that the prognostic impact of BCAR1 expression was limited to ERG-negative cancer. That BCAR1 up regulation was linked to almost all analyzed deletions $(p<0.0001$ each for PTEN, 5q, $6 \mathrm{q}$ deletion) may suggest a functional link to genomic instability.

Conclusion: The results of our study identify BCAR1 as a prognostic biomarker with potential clinical value for risk stratification of ERG-negative prostate cancer.
\end{abstract}

Keywords: BCAR1, Prostate cancer, Tissue microarray, Prognosis, Immunohistochemistry

\section{Background}

Prostate cancer is the most common cancer in men in Western societies [1]. At diagnosis the majority of prostate cancer is curable, but a minor subset of tumors is characterized by aggressive growth and metastasis. Despite recent advance in research for biomarkers, the established pre-treatment prognostic parameters are Gleason score, tumor extent on biopsy, pre-operative PSA and clinical parameters. These data are statistically

\footnotetext{
* Correspondence: R.Simon@uke.de

${ }^{\dagger}$ Equal contributors

${ }^{1}$ Institute of Pathology, University Medical Center Hamburg-Eppendorf,

Martinistr. 52, 20246 Hamburg, Germany

Full list of author information is available at the end of the article
}

powerful but not sufficient for optimal individual treatment choice. It is therefore hoped that the analysis of further biomarkers may lead to improved individual prediction of tumor aggressiveness in the future.

Breast cancer anti-estrogen resistance 1 (BCAR1/ p130Cas) is a scaffold protein that serves as a hub in cellular signaling. It facilitates the assembly of multiprotein complexes regulating diverse cellular processes such as migration, invasion, proliferation and survival. BCAR1 participates in signal conduction of major oncogenic kinases such as Abl, FAK and Src. Consequently, BCAR1 has been shown to be overexpressed in diverse malignancies, including cancers of the breast, lung, liver and brain, and has been linked to adverse features in 

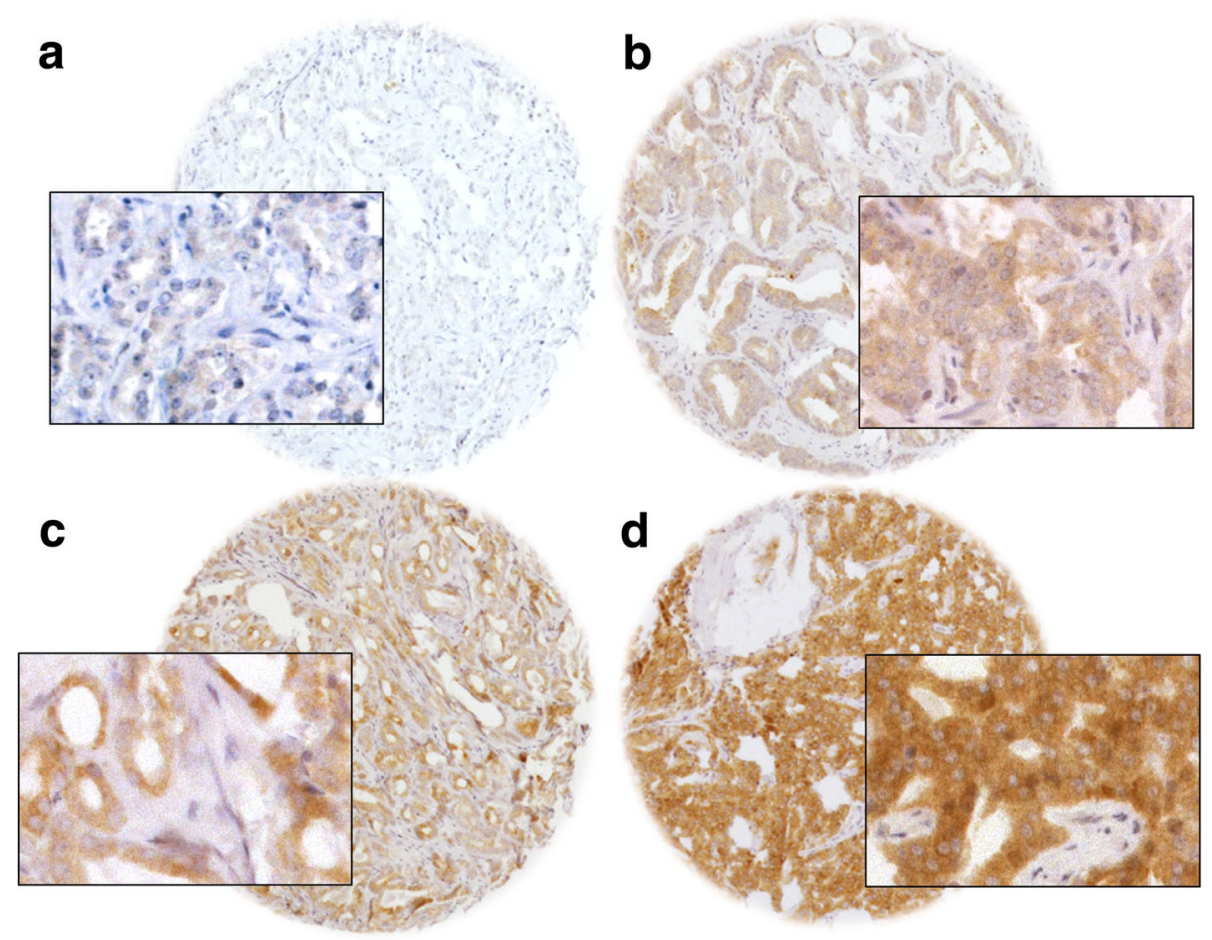

Fig. 1 Representative image of BCAR1 expression (a) negative, (b) weak, (c) moderate, (d) strong staining at 100x, and 400x (inset) magnification

these entities (reviewed in [2, 3]). Initial evidence also suggests a role for BCAR1 in prostate cancer progression, as its overexpression was linked to an unfavorable tumor phenotype and biochemical relapse in three studies analyzing 110 [4], 130 [5] and 242 [6] prostate cancer specimens.

Based on these data, we intended to confirm the biologic and prognostic role of BCAR1 protein in a very

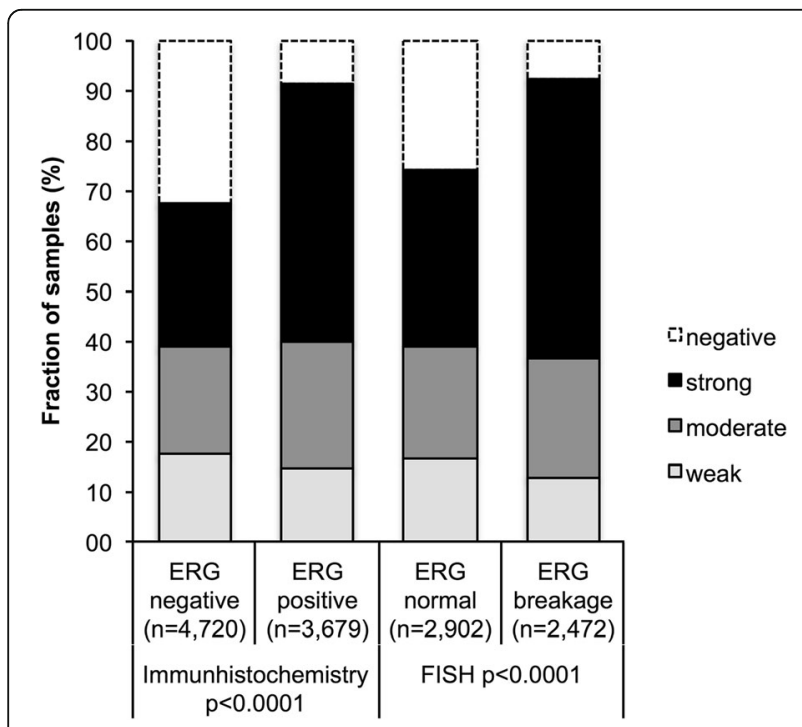

Fig. 2 Association between BCAR1 staining and ERG-status large cohort of prostate cancer patients. For this purpose, we chose our tissue microarray (TMA) comprising $>11,000$ prostate cancer specimens with attached clinical and molecular data. Our study highlight that BCAR1 expression is associated with unfavorable tumor features and that the prognostic impact of BCAR1 is limited to ERG-negative cancers.

\section{Methods}

\section{Patients}

Radical prostatectomy samples were taken from 11,152 patients, undergoing surgery between 1992 and 2011 at the Department of Urology and the Martini Clinics at the University Medical Center Hamburg-Eppendorf. Follow-up was available from 9695 patients (median 36.8 months; range 1 to 228 months; Additional file 1: Table S1). Prostate specific antigen (PSA) recurrence was defined as a postoperative PSA of $\geq 0,2 \mathrm{ng} / \mathrm{ml}$. Histological analysis of prostate specimen was done as detailed in [7] and TMA were produced as described earlier in [8]. Each TMA block contained various control tissues, including normal prostate tissue. The molecular database attached to this TMA contained results on Ki67 expression in 7010 (expanded from [9]), ERG expression in 9628, ERG break apart fluorescence in-situ hybridization (FISH) analysis in 6106 (expanded from [10]), and deletion status of 5q21 in 3037 (expanded from [11]), 6q15 in 3528 (expanded from [12]), PTEN in 
Table 1 Association between BCAR1 staining and prostate cancer clinical characteristics

\begin{tabular}{|c|c|c|c|c|c|c|}
\hline \multirow[t]{2}{*}{ Parameter } & \multicolumn{6}{|l|}{ BCAR1 (\%) } \\
\hline & $\mathrm{N}$ evaluable & Negative & Weak & Moderate & Strong & $P$ value \\
\hline All cancers & 9472 & 22.4 & 15.9 & 23.2 & 38.5 & \\
\hline \multicolumn{7}{|l|}{ Tumor stage } \\
\hline pT2 & 6170 & 23.7 & 15.9 & 23.1 & 37.4 & \multirow[t]{3}{*}{0.0082} \\
\hline рT3a & 2138 & 20.4 & 16.1 & 24.2 & 39.3 & \\
\hline pT3b-pT4 & 1160 & 19.5 & 15.6 & 21.7 & 43.2 & \\
\hline \multicolumn{7}{|l|}{ Gleason score } \\
\hline$\leq 3+3$ & 2186 & 27.2 & 19.0 & 23.1 & 30.8 & \multirow[t]{6}{*}{$<0.0001$} \\
\hline $3+4$ & 5133 & 21.9 & 14.9 & 23.5 & 39.8 & \\
\hline $3+4$ Tertiary 5 & 345 & 22.9 & 14.5 & 23.8 & 38.8 & \\
\hline $4+3$ & 893 & 18.4 & 17.6 & 21.7 & 42.3 & \\
\hline $4+3$ Tertiary 5 & 464 & 15.1 & 14.4 & 22.4 & 48.1 & \\
\hline$\geq 4+4$ & 445 & 20.9 & 11.7 & 23.2 & 44.3 & \\
\hline \multicolumn{7}{|c|}{ Lymph node metastasis } \\
\hline No & 5262 & 20.9 & 16.1 & 23.2 & 40.0 & \multirow[t]{2}{*}{$<0.0001$} \\
\hline $\mathrm{N}+$ & 494 & 21.3 & 12.8 & 21.5 & 44.5 & \\
\hline \multicolumn{7}{|c|}{ Preoperative PSA level (ng/ml) } \\
\hline$<4$ & 1480 & 16.9 & 15.0 & 24.0 & 44.1 & \multirow[t]{4}{*}{$<0.0001$} \\
\hline $4-10$ & 5475 & 21.6 & 15.9 & 23.5 & 39.0 & \\
\hline $10-20$ & 1817 & 26.0 & 15.9 & 22.5 & 35.6 & \\
\hline$>20$ & 638 & 32.1 & 17.6 & 19.0 & 31.4 & \\
\hline \multicolumn{7}{|l|}{ Surgical margin } \\
\hline Negative & 7566 & 22.1 & 15.8 & 23.3 & 38.8 & \multirow[t]{2}{*}{$<0.0001$} \\
\hline Positive & 1794 & 23.4 & 16.2 & 22.9 & 37.6 & \\
\hline
\end{tabular}

6130 (expanded from [13]), and 3p13 in 1290 (expanded from [14]) tumors.

\section{Immunohistochemistry}

Freshly cut TMA sections were stained on 1 day and in one experiment. Slides were deparaffinized and exposed to heat-induced antigen retrieval at $121{ }^{\circ} \mathrm{C}$ in Tris-EDTA-citrate buffer (pH 7.8). BCAR1 specific mouse monoclonal antibody (clone M144, Abcam, Cambridge, UK) was applied at $1 / 37.5$ dilution at $37^{\circ}$ $\mathrm{C}$ for $60 \mathrm{~min}$. BCAR1 staining was visualized with the EnVision Kit (Dako, Glostrup, Denmark) according to the manufacturer's directions. Staining was localized to the cytoplasm. It was homogenous in the analyzed tissue samples and therefore staining intensity was semi quantitatively assessed as negative, weak, moderate, and strong.

\section{Statistics}

JPM 9 software (SAS Institute Inc., NC, USA) was used. Contingency tables and the likelihood-ratio chi2-test were performed to find associations between molecular parameters and clinical tumor characteristics. Kaplan-Meier survival curves were calculated and the Log-Rank test was applied to detect differences. Cox proportional hazards regression was performed to look for statistical independence of pathological, molecular and clinical variables. Separate analyses were done using various sets of parameters available either before or after prostatectomy.

\section{Results}

Technical issues

Eighty four point nine percent of the 11,152 arrayed tumor samples were interpretable in our TMA analysis. $15.1 \%$ were non-informative, which included 1679 spots with lack of tissue samples or absence of unequivocal cancer tissue in the TMA spot.

\section{BCAR1 expression}

BCAR1 staining was generally absent or very faint in normal prostatic secretory cells, basal cells and stromal cells. In cancer cells, cytoplasmic BCAR1 expression was observed in $77.6 \%$ of 9472 interpretable prostate cancers; weak in $15.9 \%$, moderate in $23.2 \%$, and strong in $38.5 \%$ of cases. Fig. 1 shows representative images. BCAR1 
Table 2 Association between BCAR1 expression and Ki67-labeling index in different Gleason scores

\begin{tabular}{|c|c|c|c|c|c|}
\hline \multirow[t]{2}{*}{ Gleason score } & \multirow[t]{2}{*}{ BCAR1 expression } & \multirow{2}{*}{$\begin{array}{l}\text { Ki67- } \\
\mathrm{N}\end{array}$} & \multirow{2}{*}{$\begin{array}{l}\text { labeling } \\
\text { Mean }\end{array}$} & \multirow{2}{*}{$\begin{array}{l}\text { index } \\
\pm S D\end{array}$} & \multirow[t]{2}{*}{$P$ value } \\
\hline & & & & & \\
\hline \multirow[t]{4}{*}{ All } & Negative & 1422 & 1.6 & 0.07 & $<0.0001$ \\
\hline & Weak & 1063 & 2.5 & 0.08 & \\
\hline & Moderate & 1467 & 2.8 & 0.07 & \\
\hline & Strong & 2390 & 3.5 & 0.05 & \\
\hline \multirow[t]{4}{*}{$\leq 3+3$} & Negative & 391 & 1.3 & 0.10 & $<0.0001$ \\
\hline & Weak & 267 & 2.3 & 0.13 & \\
\hline & Moderate & 295 & 2.4 & 0.12 & \\
\hline & Strong & 406 & 2.8 & 0.10 & \\
\hline \multirow[t]{4}{*}{$3+4$} & Negative & 747 & 1.5 & 0.08 & $<0.0001$ \\
\hline & Weak & 552 & 2.4 & 0.10 & \\
\hline & Moderate & 846 & 2.6 & 0.08 & \\
\hline & Strong & 1387 & 3.3 & 0.06 & \\
\hline \multirow[t]{4}{*}{$3+4$ Tertiary 5} & Negative & 61 & 2.0 & 0.32 & $<0.0001$ \\
\hline & Weak & 45 & 2.6 & 0.37 & \\
\hline & Moderate & 59 & 3.4 & 0.32 & \\
\hline & Strong & 96 & 3.9 & 0.25 & \\
\hline \multirow[t]{4}{*}{$4+3$} & Negative & 115 & 1.8 & 0.29 & $<0.0001$ \\
\hline & Weak & 115 & 2.8 & 0.29 & \\
\hline & Moderate & 126 & 3.0 & 0.27 & \\
\hline & Strong & 233 & 4.2 & 0.20 & \\
\hline \multirow[t]{4}{*}{$4+3$ Tertiary 5} & Negative & 50 & 2.0 & 0.53 & $<0.0001$ \\
\hline & Weak & 47 & 3.4 & 0.54 & \\
\hline & Moderate & 72 & 3.8 & 0.44 & \\
\hline & Strong & 147 & 4.8 & 0.31 & \\
\hline \multirow[t]{4}{*}{$\geq 4+4$} & Negative & 58 & 3.5 & 0.63 & $<0.0001$ \\
\hline & Weak & 36 & 4.0 & 0.80 & \\
\hline & Moderate & 68 & 4.6 & 0.58 & \\
\hline & Strong & 118 & 5.5 & 0.44 & \\
\hline
\end{tabular}

expression correlated with the expression of the androgen receptor (Additional file 1: Figure S3).

\section{Associations with TMPRSS2:ERG fusion status and ERG protein expression}

To evaluate whether BCAR1 expression is associated with ERG rearrangements in prostate cancers, we used pre-existing data on ERG status obtained by FISH in 5379 cancers and by IHC in 8421 tumors for which BCAR1 staining was also available. Data on both ERG FISH and ERG IHC were available from 5938 cancers, and an identical result (ERG IHC positive and rearrangement by FISH or ERG IHC negative and missing rearrangement by FISH) was found in 5666 of $5938(95.4 \%)$ cancers. The level of BCAR1 staining was associated with the presence of ERG rearrangements and ERG expression in prostate cancers $(p<0.0001$ each; Fig. 2). For example, moderate or strong BCAR1 staining was observed in $79.3 \%$ of cancers with ERG rearrangement detected by $\mathrm{FISH}$ but found in only $57.3 \%$ of cancers without such rearrangements $(p<0.0001)$.

\section{Associations with clinical tumor characteristics}

High BCAR1 staining was associated with advanced tumor stage $(p=0.008)$, high Gleason score $(p<0.0001)$ and low preoperative PSA level $(p<0.0001)$ when all cancers were jointly analyzed (Table 1 , Additional file 1 : Figure S4 and S5). Subset analysis of ERG-negative and ERG-positive cancer revealed that these associations were largely driven by the subset of ERG-negative cancers (Additional file 1: Table S2), while most differences were only small in ERG-positive cancers (Additional file 1: Table S2). For example, in ERG-negative cancer, strong BCAR1 expression was found in $27.9 \%$ of pT2 cancers and increased by $9.3 \%$ to $37.2 \%$ in tumors $\geq$ pT3b, while the difference in ERG-positive cancer was only $1.7 \%$ between pT2 (51.9\%) and $\geq$ pT3b (50.2\%). That significant $p$-values were obtained despite these small differences is most likely due to the very high numbers of cancers included in our analysis.

\section{Association to cell proliferation}

Increased BCAR1 staining was linked to accelerated cell proliferation. Although this association was found when all cancers were jointly analyzed $(p<0.0001$; Table 2), subset analysis revealed that it was largely driven by ERG-negative tumors (Additional file 1: Table S3). Here, the Ki67 labeling index (Li) ranged from $1.5 \%$ (in BCAR1 negative cancer) to $4.0 \%$ (in strongly BCAR1 positive cancer, $p<0.0001)$, while this association was weaker $(2.2 \%$ in BCAR1 negative vs. $3.2 \%$ in BCAR1 strong, $p<0.0001)$ in ERG-positive cancer. Further subset analysis showed that the association was independent from the Gleason score in ERG-negative cancer, because they held true in subsets of cancers with identical Gleason score. Such an unequivocal independent association was lacking in ERG-positive cancer.

\section{Relationship with key genomic deletions in ERG-positive and ERG-negative prostate cancers}

Previous observations had prostate cancer divided in distinct molecular subgroups defined by TMPRSS2:ERG fusion and various genomic deletions. Others and us reported strong association between deletions involving the chromosomal region of PTEN and 3p13 with the presence of ERG fusions and deletions of 5 q21 and $6 q 15$ with lack of ERG fusions [11-16]. High BCAR1 staining was associated with PTEN deletion $(p<0.0001)$ and 


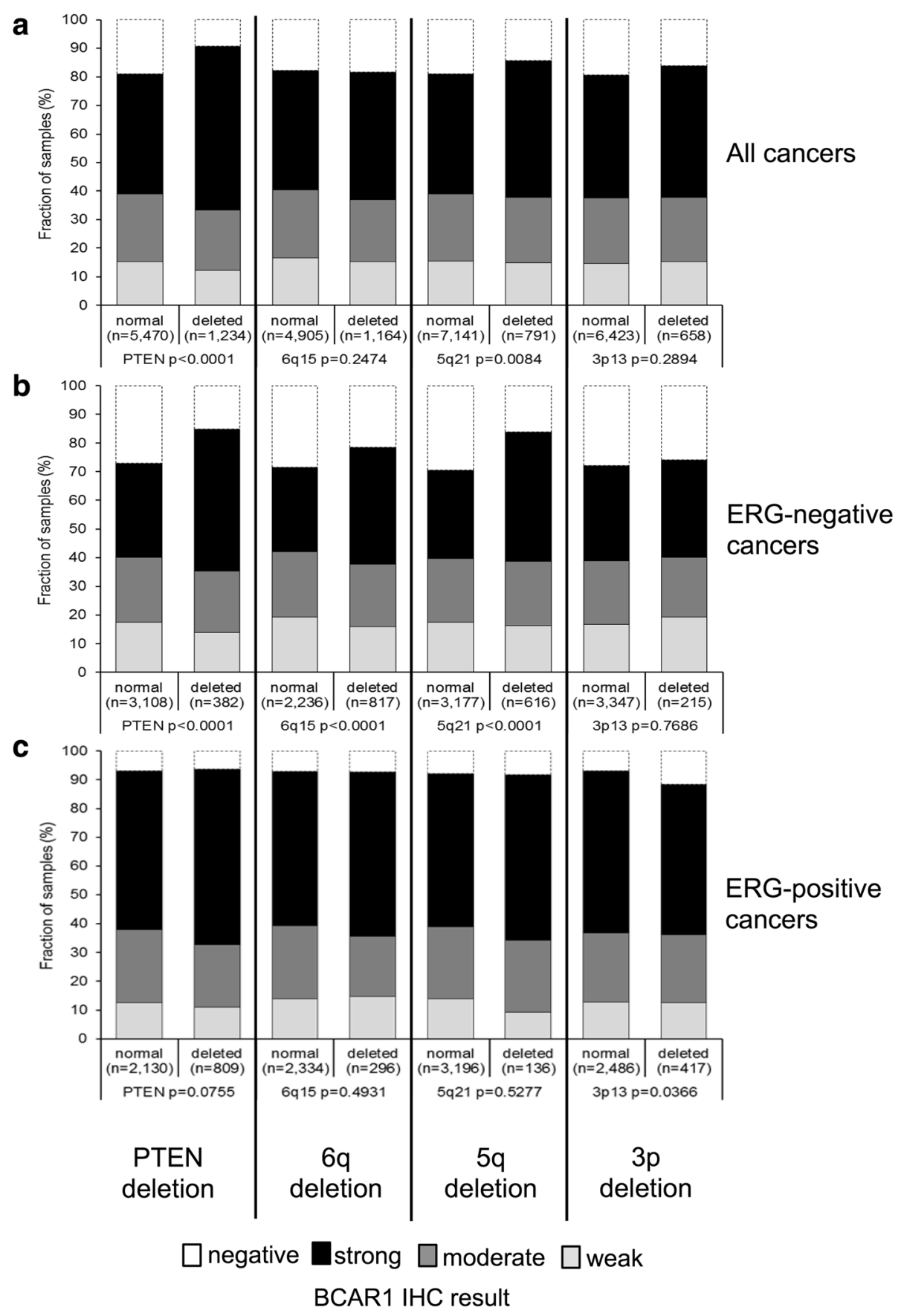

Fig. 3 Association between BCAR1 staining and 10q23 (PTEN), 6q21 (MAP3K7), $5 q 21$ (CHD1), 3p13 (FOXP1) deletion in (a) all cancers, (b) the ERG-negative and (c) -positive subset

marginally associated with deletions of CHD1 (5q21) $(p=0.0084)$ when all cancers were jointly analyzed (Fig. 3a). In ERG-negative cancer, high levels of BCAR1 expression were significantly linked to presence of deletions of PTEN $(p<0.0001)$, CHD1 (5q21) $(p<0.0001)$ and MAP3K7 (6q15) $(p<0.0001$; Fig. 3b), while these associations were lost in ERG-positive cancer (Fig. 3c).

\section{BCAR1 and clinical outcome}

Follow-up was available for 8255 patients with informative BCAR1 data. Strong versus negative BCAR1 expression was associated with early PSA recurrence in all tumors (Fig. 4a) and was limited in subgroup analyses to the subset of ERG-negative cancer (Fig. 4b,c). To better understand the prognostic power of BCAR1, we performed further subset analysis in cancers with identical 


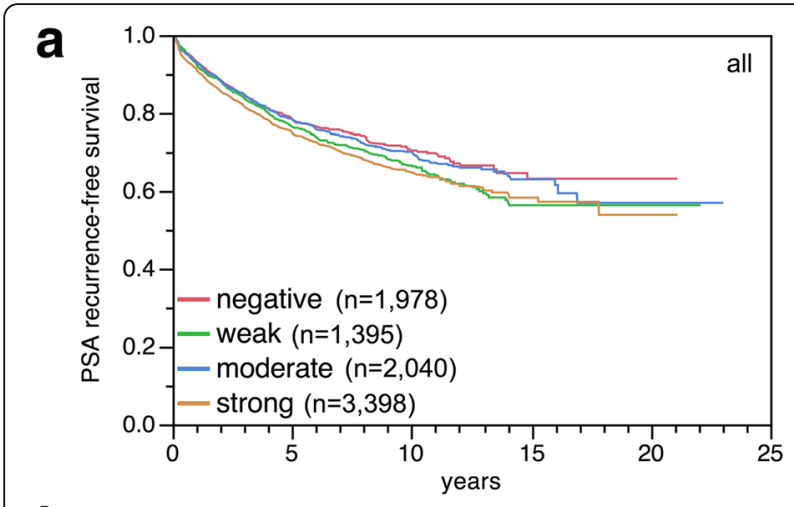

b

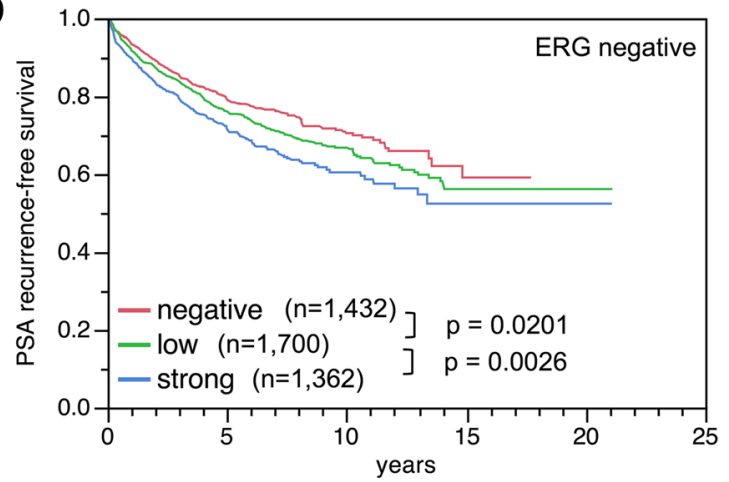

C

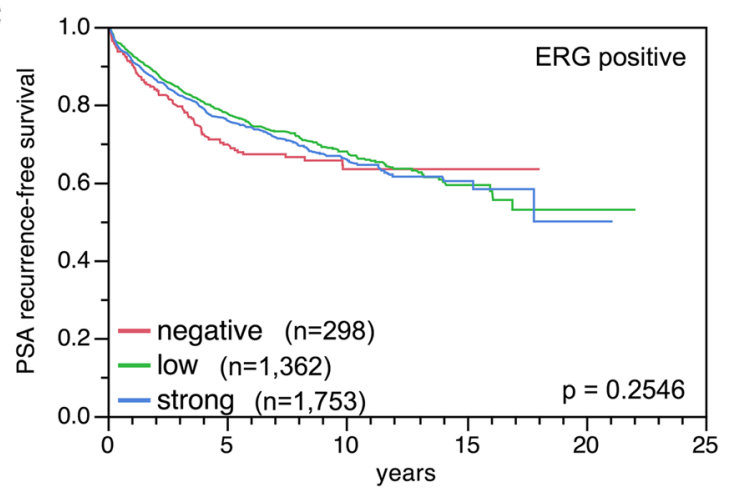

Fig. 4 Kaplan-Meier plots of prostate specific antigen (PSA) recurrence after radical prostatectomy and BCAR1 staining in (a) all cancers, (b) the ERG-negative and (c) -positive subset. Low level combines cases with weak and moderate BCAR1 expression, which had similar prognosis

classical and quantitative Gleason score in all patients (Additional file 1: Figure S1) and the ERG negative subset (Additional file 1: Figure S2). Here, BCAR1 staining did not provide significant prognostic information beyond the classical Gleason score (Additional file 1: Figures S1a and S2a) or the quantitative Gleason score (Additional file 1: Figures S1b-h and S2b-h).

\section{Multivariate analysis}

In order to test whether the prognostic impact of BCAR1 was independent from established prognostic parameters, four multivariate analyses were done to evaluate the relevance of BCAR1 expression in different clinical scenarios (Table 3 ). In scenario 1 , the preoperatively available parameters (preoperative PSA value, clinical stage, and Gleason score at biopsy) were jointly analyzed with the BCAR1 expression level. In scenario 2, the biopsy Gleason was replaced by the Gleason score obtained at radical prostatectomy. In scenario 3 clinical stage is superseded by pathological tumor stage and surgical margin and in scenario 4 the lymph node status is added. The BCAR1 expression level remained marginally significant in pre - and postoperative scenarios with hazard ratios for PSA recurrence-free survival from 1.14 to 1.29 .

\section{Discussion}

The results of this study suggest that high BCAR1 expression is a weak independent predictor of unfavorable tumor characteristics and early PSA recurrence. Consistent with earlier findings [5], BCAR1 staining was barely detectable in luminal cells of non-neoplastic prostatic glands but clearly up regulated in a large fraction of prostate cancers, which suggests a role for BCAR1 during prostate cancer development. The analysis revealed cytoplasmic BCAR1 staining in $76.6 \%$ of 9495 analyzable prostate cancers. These numbers fit well to previous TMA based studies, which reported up to $90 \%$ of BCAR1 positivity in sets of 110 up to 242 prostate carcinomas [4-6].

BCAR1 up regulation was linked to aggressive cancer features in our study, including high Gleason score, advanced tumor stage, presence of lymph node metastases, rapid tumor cell proliferation and early biochemical recurrence, arguing for a contribution of elevated BCAR1 protein expression to prostate cancer progression. These findings are supported by the results of several earlier studies suggesting associations between BCAR1 up regulation and advanced prostate cancer features such as castration resistance, metastasis and early biochemical relapse [4-6]. A tumor promoting role of BCAR1 overexpression fits well to the known function of BCAR1, which serves as a hub for several oncogenic pathways regulating processes like cell proliferation, growth, migration, and other cancer relevant cellular functions (reviewed in $[2,3]$ ).

The molecular database attached to our TMA allowed us to draw conclusions on molecular mechanisms associated with BCAR1 up regulation. It is well known that about the half of prostate cancers carry a gene fusion, which links the androgen-regulated serine protease TMPRSS2 with the ETS-transcription factor ERG resulting in an androgen-related expression of ERG with subsequent dysregulation of more than 1600 ERG target genes [17-19]. BCAR1 up regulation was strongly linked to TMPRSS2:ERG fusions in our study. ERG does not 
Table 3 Hazard ratio of PSA recurrence-free survival of established prognostic parameters and BCAR1 expression

\begin{tabular}{|c|c|c|c|c|c|}
\hline & Scenario & 1 & 2 & 3 & 4 \\
\hline & Analyzable (N) & 8522 & 8662 & 8778 & 5362 \\
\hline \multirow[t]{16}{*}{ Preoperative } & \multicolumn{5}{|l|}{ Gleason score biopsy } \\
\hline & $3+4$ vs. $\leq 3+3$ & \multicolumn{4}{|l|}{$1.98^{* * *}$} \\
\hline & $4+3$ vs. $3+4$ & \multicolumn{4}{|l|}{$1.62^{* * *}$} \\
\hline & $\geq 4+4$ vs. $4+3$ & \multicolumn{4}{|l|}{$1.30^{* * *}$} \\
\hline & \multicolumn{5}{|l|}{ Clinical tumor (cT) stage } \\
\hline & T2a vs. T1c & $1.33^{* * *}$ & \multicolumn{3}{|l|}{$1.33^{* * *}$} \\
\hline & T2b vs. T2a & $1.47^{* * *}$ & \multicolumn{3}{|l|}{$1.40^{* * *}$} \\
\hline & T3a vs. T2c & $0.62^{*}$ & \multicolumn{3}{|l|}{$0.65^{*}$} \\
\hline & \multicolumn{5}{|l|}{ Preoperative PSA level } \\
\hline & $4-10$ vs. $<4$ & $1.45^{* * *}$ & $1.38^{* *}$ & $1.21^{*}$ & 1.17 \\
\hline & $10-20$ vs. $4-10$ & $1.52^{* * *}$ & $1.43^{* * *}$ & $1.28^{* * *}$ & $1.19^{*}$ \\
\hline & $>20$ vs. $10-20$ & $1.69 * * *$ & $1.53 * * *$ & $1.20 *$ & $1.19^{*}$ \\
\hline & \multicolumn{5}{|l|}{ BCAR1 expression } \\
\hline & Weak vs. negative & $1.17^{*}$ & 1.14 & $1.16^{*}$ & $1.29^{*}$ \\
\hline & Moderate vs. weak & 0.91 & 0.92 & 0.88 & $0.78 *$ \\
\hline & Strong vs. moderate & $1.14^{*}$ & 1.08 & 1.12 & 1.13 \\
\hline \multirow[t]{12}{*}{ Postoperative } & \multicolumn{5}{|c|}{ Gleason score prostatectomy } \\
\hline & \multicolumn{2}{|l|}{$3+4$ vs. $\leq 3+3$} & $3.05^{* * *}$ & $2.48^{* * *}$ & $2.24^{* * *}$ \\
\hline & \multicolumn{2}{|l|}{$4+3$ vs. $3+4$} & $2.56^{* * *}$ & $2.13^{* * *}$ & $2.01^{* * *}$ \\
\hline & \multicolumn{2}{|l|}{$\geq 4+4$ vs. $4+3$} & $1.70^{* * *}$ & $1.20^{*}$ & 1.11 \\
\hline & \multicolumn{5}{|c|}{ Pathological tumor (pT) stage } \\
\hline & \multicolumn{3}{|l|}{ T3a vs. T2 } & $2.00^{* * *}$ & $2.03^{* * *}$ \\
\hline & \multicolumn{3}{|l|}{ T3b vs. T3a } & $1.72^{* * *}$ & $1.55^{* * *}$ \\
\hline & \multicolumn{3}{|l|}{ T4 vs. T3b } & $1.38^{*}$ & 1.35 \\
\hline & \multicolumn{5}{|c|}{ Surgical margin (R) status } \\
\hline & \multicolumn{3}{|l|}{ R1 vs. R0 } & $1.44^{* * *}$ & $1.31^{* * *}$ \\
\hline & \multicolumn{5}{|l|}{ Lymph node $(\mathrm{N})$ status } \\
\hline & \multicolumn{3}{|l|}{$\mathrm{N}+$ vs. NO } & & $1.44^{* * *}$ \\
\hline
\end{tabular}

Scenario 1 combines preoperatively available parameter (preoperative Gleason score obtained on the original biopsy, clinical tumor (cT) stage, and preoperative PSA) with the postoperative BCAR1 expression. In scenario 2 the biopsy Gleason is replaced by the Gleason score obtained on radical prostatectomy (RPE). In scenario $3 \mathrm{cT}$-stage is superseded by pathological tumor ( $\mathrm{pT}$ ) stage and surgical margin (R) status. In scenario 4 the lymph node (pN) stage is added. Asterisk indicate significance level: ${ }^{*} p \leq 0.05,{ }^{* *} p \leq 0.001$, and ${ }^{* *} p \leq 0.0001$

seem to be implicated in transcriptional control of BCAR1 based on the results of studies analyzing global transcriptional changes between ERG-negative and ERGpositive prostate cancers $[15,19-22]$. It is, thus, possible that post-transcriptional modifications may account for the different BCAR1 expression levels in ERG-positive and ERG-negative cancers, including for example altered protein stability. This assumption is supported by studies demonstrating that ERG activation modulates the activity of the reversible protein ubiquitination cascade [15, 23], including the E3 ubiquitin ligase SKP2 that regulates stability of the BCAR1/p130CAS protein [24-26].

The association between BCAR1 expression and lymph node metastasis was puzzling because it was in the opposite direction between the ERG negative and positive cancers and significant in both subsets (Additional file 1: Table S2). We assume a complex situation as a result of 1) minor differences resulting in high statistical significance because of the very high sample numbers, 2) ERG driven sudden up-regulation of BCAR1 expression and 3) regression to the mean in tumor progression to nodal metastasis which means increase of BCAR1 staining in the ERG negative and decrease of BCAR1 staining in the ERG positive cancer subset.

In prostate cancer are after the TMPRSS2: ERG fusion, chromosomal deletions the most frequent type of genomic aberration. They occur at frequencies of up to $40 \%$ $[15,27]$ and are associated with poor prognosis [11-15]. 
Deletion of PTEN (20\%), 6q (20\%), 5q (10\%) and 3p (10\%) are linked to either positive ERG status (PTEN, $3 p)$ or negative ERG status (6q, 5q). In our study, BCAR1 up regulation was associated with most of these deletions (PTEN, 5q21, and 6q15). This finding is consistent with earlier work linking altered BCAR1 activity to development of genetic instability [28]. It has been shown that BCAR1 can translocate to the nucleus under hypoxic conditions, where it specifically impairs the homologous repair (HR) protein RAD51 [28]. Several studies have demonstrated that RAD51 deficiency can induce replication defects, genetic instability and chromosomal rearrangements $[29,30]$.

In previous studies, we identified several proteins, which were also expressed at higher levels in ERGpositive than in ERG-negative prostate cancer. In some of these, the prognostic effect was likewise restricted to the ERG-negative subset [31-33]. Here we identify BCAR1 as a protein following this pattern. In opposite some other biomarker were only prognostic in ERG-positive cancer [32, 34]. Together, these data show that tumor relevant functions of BCAR1 and other proteins turn out to be attenuated or amplified by ERG. ERG seems to be a critical modifier of the intracellular environment $[19,20$, 23]. These challenge the concept of a unique prognostic molecular test applicable to all patients [35, 36]. It appears possible that different tests need to be developed for ERG-positive and ERG-negative cancer. Furthermore, the small difference of about $10 \%$ in Kaplan-Meier plots between negative and strongly positive BCAR1 expression, shows that BCAR1 seems to be a weak prognostic marker (Fig. 4). Thus the BCAR1 biomarker may best aid in decision making if combined with other marker in ERG-negative prostate cancer.

It is of note that the Gleason score had the highest hazard ratio for PSA recurrence-free survival in multivariate analysis and is therefore the strongest (and less expensive) prognostic marker in prostate cancer. We demonstrated recently, that with the percentage of unfavorable Gleason patterns, Gleason grading could be transformed from a categorical into a continuous variable (i.e., the quantitative Gleason score) with subtler distinction of prognosis [37]. The power of morphological methods competing with biomarkers for predicting prostate cancer aggressiveness is best demonstrated by the separate analysis of different prognostic Gleason groups. That the prognostic impact of BCAR1 was lost in groups defined by classical Gleason score categories or by the quantitative Gleason score demonstrates how difficult it is for a biomarker to outperform a morphological malignancy score.

\section{Conclusions}

The results of our study demonstrate that BCAR1 is an ERG subset specific prognostic biomarker. The minor prognostic difference between cancers with negative or strong BCAR1 expression limits its clinical impact as a stand-alone marker. However, BCAR1 may be a useful marker if combined with other molecular markers, especially for ERG-negative prostate cancer.

\section{Additional files}

\begin{abstract}
Additional file 1: Figure S1. Kaplan-Meier plots of prostate specific antigen (PSA) recurrence after radical prostatectomy and negative or strong BCAR1 staining in subsets of all cancers defined by (a) classical Gleason score, (b-h) quantitative Gleason score defined by the percentage of Gleason 4 grade and (i-j) by the tertiary Gleason 5 grade. Figure S2. Kaplan-Meier plots of prostate specific antigen (PSA) recurrence after radical prostatectomy and BCAR1 staining in subsets of ERG negative cancers defined by (a) classical and (b-h) quantitative Gleason score, defined by the percentage of Gleason 4 grade and $(i-j)$ by the tertiary Gleason 5 grade. Figure S3. Correlation of BCAR1 staining and androgen receptor (AR) staining in all cancers, Figure S4. Kaplan-Meier plot of prostate specific antigen (PSA) recurrence after radical prostatectomy and clinical stage in all cancers, Figure S5. Kaplan-Meier plot of prostate specific antigen (PSA) recurrence after radical prostatectomy and Gleason score at biopsy in all cancers, Table S1. Pathological and clinical data of the arrayed prostate cancer, Table S2. Association between BCAR1 staining and prostate cancer clinical characteristics in ERG-fusion negative and positive subsets, Table S3. Association between BCRA1 expression and Ki67-labeling index depending on ERG-fusion status in different Gleason scores. (DOC $5580 \mathrm{~kb}$ )
\end{abstract}

\section{Abbreviations}

BCAR1: Breast cancer anti-estrogen resistance 1; CHD1: Chromodomainhelicase-DNA-binding protein 1; ERG: Erythroblast transformation-specific (ETS) related gene; FISH: Fluorescence in situ hybridization; FOXP1: Fork head box protein P1; Ki67LI: Ki67 labeling index; MAP3K7: Mitogen-activated protein kinase kinase kinase 7; PSA: Prostate specific antigen;

PTEN: Phosphatase and tensin homolog; TMA: Tissue microarray;

TMPRSS2: Trans membrane protease, serine 2

\section{Acknowledgements}

The authors appreciate the excellent technical support of Sylvia Schnöger and Sasha Eghtessadi.

Funding

No specific funding was received for this study.

Availability of data and materials

All data generated or analyzed during this study are included in this published article [and its supplementary information files].

\section{Authors' contributions}

$\mathrm{AH}, \mathrm{NH}, \mathrm{GS}, \mathrm{RS}$ and $\mathrm{AHi}$ conceived and designed the study, analyzed the data and drafted the manuscript. NH, CMK and SM performed most of the key immunohistochemical analyses. GS and RS were involved in the original conception of the study. DL, MCT, MK, CHM and HHu provided data. KG, SM, CW, SS, FJ, and PL participated in tissue processing, pathological diagnosis and immunohistochemical analysis. MG, HH, WW, RS and TS provided materials, clinical follow-up data and technical assistance. All authors have read and approved the manuscript.

\section{Ethics approval and consent to participate}

The ethics committee of the Ärztekammer Hamburg approved this study (WF-049/09 and PV3652). According to local laws (HmbKHG, §12,1) informed consent was not required for this study. 


\section{Consent for publication}

Not applicable.

\section{Competing interests}

All authors declare that they have no competing interests.

\section{Publisher's Note}

Springer Nature remains neutral with regard to jurisdictional claims in published maps and institutional affiliations.

\section{Author details}

'Institute of Pathology, University Medical Center Hamburg-Eppendorf, Martinistr. 52, 20246 Hamburg, Germany. ${ }^{2}$ General, Visceral and Thoracic Surgery Department and Clinic, University Medical Center Hamburg-Eppendorf, Martinistr. 52, Hamburg, Germany. ${ }^{3}$ Martini-Clinic, Prostate Cancer Center, University Medical Center Hamburg-Eppendorf, Martinistr. 52, Hamburg, Germany. ${ }^{4}$ Department of Urology, Section for translational Prostate Cancer Research, University Medical Center Hamburg-Eppendorf, Martinistr. 52, Hamburg, Germany.

Received: 16 June 2017 Accepted: 21 December 2017

\section{Published online: 05 January 2018}

\section{References}

1. Siegel R, Naishadham D, Jemal A. Cancer statistics, 2013. CA Cancer J Clin. 2013;63(1):11-30.

2. Camacho Leal Mdel P, Sciortino M, Tornillo G, Colombo S, Defilippi P, Cabodi S. p130Cas/BCAR1 scaffold protein in tissue homeostasis and pathogenesis. Gene. 2015;(1):562, 1-7.

3. Barrett A, Pellet-Many C, Zachary IC, Evans IM, Frankel P. p130Cas: a key signalling node in health and disease. Cell Signal. 2013;25(4):766-77.

4. Celhay O, Yacoub M, Irani J, Dore B, Cussenot O, Fromont G. Expression of estrogen related proteins in hormone refractory prostate cancer: association with tumor progression. J Urol. 2010;184(5):2172-8.

5. Fromont $G$, Vallancien $G$, Validire $P$, Levillain $P$, Cussenot O. BCAR1 expression in prostate cancer: association with $16 \mathrm{q} 23 \mathrm{LOH}$ status, tumor progression and EGFR/KAl1 staining. Prostate. 2007;67(3):268-73.

6. Fromont G, Rozet F, Cathelineau X, Ouzzane A, Doucet L, Fournier G, Cussenot O. BCAR1 expression improves prediction of biochemical reccurence after radical prostatectomy. Prostate. 2012;72(12):1359-65.

7. Erbersdobler A, Fritz H, Schnoger S, Graefen M, Hammerer P, Huland H, Henke RP. Tumour grade, proliferation, apoptosis, microvessel density, p53, and bcl-2 in prostate cancers: differences between tumours located in the transition zone and in the peripheral zone. Eur Urol. 2002;41(1):40-6.

8. Mirlacher M, Simon R. Recipient block TMA technique. Methods Mol Biol. 2010;664:37-44.

9. Minner S, Jessen B, Stiedenroth L, Burandt E, Kollermann J, Mirlacher M, Erbersdobler A, Eichelberg C, Fisch M, Brummendorf TH, et al. Low level HER2 overexpression is associated with rapid tumor cell proliferation and poor prognosis in prostate cancer. Clin Cancer Res. 2010;16(5):1553-60.

10. Minner S, Enodien M, Sirma H, Luebke AM, Krohn A, Mayer PS, Simon R, Tennstedt P, Muller J, Scholz L, et al. ERG status is unrelated to PSA recurrence in radically operated prostate cancer in the absence of antihormonal therapy. Clin Cancer Res. 2011;17(18):5878-88.

11. Burkhardt L, Fuchs S, Krohn A, Masser S, Mader M, Kluth M, Bachmann $F$, Huland $H$, Steuber T, Graefen M, et al. CHD1 is a 5 q21 tumor suppressor required for ERG rearrangement in prostate cancer. Cancer Res. 2013;73(9):2795-805.

12. Kluth M, Hesse J, Heinl A, Krohn A, Steurer S, Sirma H, Simon R, Mayer PS, Schumacher U, Grupp K, et al. Genomic deletion of MAP3K7 at $6 q 12-22$ is associated with early PSA recurrence in prostate cancer and absence of TMPRSS2:ERG fusions. Mod Pathol. 2013;26(7):975-83.

13. Krohn A, Diedler T, Burkhardt L, Mayer PS, De Silva C, Meyer-Kornblum M, Kotschau D, Tennstedt P, Huang J, Gerhauser C, et al. Genomic deletion of PTEN is associated with tumor progression and early PSA recurrence in ERG fusion-positive and fusion-negative prostate cancer. Am J Pathol. 2012; 181(2):401-12.

14. Krohn A, Seidel A, Burkhardt L, Bachmann F, Mader M, Grupp K, Eichenauer T, Becker A, Adam M, Graefen M, et al. Recurrent deletion of 3 p13 targets multiple tumour suppressor genes and defines a distinct subgroup of aggressive ERG fusion-positive prostate cancers. J Pathol. 2013;231(1):130-41.
15. Taylor BS, Schultz N, Hieronymus H, Gopalan A, Xiao Y, Carver BS, Arora VK, Kaushik $\mathrm{P}$, Cerami E, Reva B, et al. Integrative genomic profiling of human prostate cancer. Cancer Cell. 2010;18(1):11-22.

16. Lapointe J, Li C, Giacomini CP, Salari K, Huang S, Wang P, Ferrari M, Hernandez-Boussard T, Brooks JD, Pollack JR. Genomic profiling reveals alternative genetic pathways of prostate tumorigenesis. Cancer Res. 2007; 67(18):8504-10

17. Weischenfeldt J, Simon R, Feuerbach L, Schlangen K, Weichenhan D, Minner S, Wuttig D, Warnatz HJ, Stehr H, Rausch T, et al. Integrative genomic analyses reveal an androgen-driven somatic alteration landscape in earlyonset prostate cancer. Cancer Cell. 2013;23(2):159-70.

18. Tomlins SA, Rhodes DR, Perner S, Dhanasekaran SM, Mehra R, Sun XW, Varambally S, Cao X, Tchinda J, Kuefer R, et al. Recurrent fusion of TMPRSS2 and ETS transcription factor genes in prostate cancer. Science. 2005; 310(5748):644-8.

19. Brase JC, Johannes M, Mannsperger H, Falth M, Metzger J, Kacprzyk LA, Andrasiuk T, Gade S, Meister M, Sirma H, et al. TMPRSS2-ERG -specific transcriptional modulation is associated with prostate cancer biomarkers and TGF-beta signaling. BMC Cancer. 2011;11:507.

20. Gupta S, Iljin K, Sara H, Mpindi JP, Mirtti T, Vainio P, Rantala J, Alanen K, Nees $\mathrm{M}$, Kallioniemi O. FZD4 as a mediator of ERG oncogene-induced WNT signaling and epithelial-to-mesenchymal transition in human prostate cancer cells. Cancer Res. 2010;70(17):6735-45.

21. Setlur SR, Mertz KD, Hoshida Y, Demichelis F, Lupien M, Perner S, Sboner A, Pawitan Y, Andren O, Johnson LA, et al. Estrogen-dependent signaling in a molecularly distinct subclass of aggressive prostate cancer. J Natl Cancer Inst. 2008;100(11):815-25.

22. Tan SH, Furusato B, Fang X, He F, Mohamed AA, Griner NB, Sood K, Saxena $S$, Katta $S$, Young D, et al. Evaluation of ERG responsive proteome in prostate cancer. Prostate. 2014;74(1):70-89.

23. Jhavar S, Brewer D, Edwards S, Kote-Jarai Z, Attard G, Clark J, Flohr P, Christmas T, Thompson A, Parker $M$, et al. Integration of ERG gene mapping and gene-expression profiling identifies distinct categories of human prostate cancer. BJU Int. 2009;103(9):1256-69.

24. Bhattacharya S, Garriga J, Calbo J, Yong T, Haines DS, Grana X. SKP2 associates with p130 and accelerates p130 ubiquitylation and degradation in human cells. Oncogene. 2003;22(16):2443-51.

25. Tedesco D, Lukas J, Reed SI. The pRb-related protein p130 is regulated by phosphorylation-dependent proteolysis via the protein-ubiquitin ligase SCF (Skp2). Genes Dev. 2002;16(22):2946-57.

26. Sengupta S, Henry RW. Regulation of the retinoblastoma-E2F pathway by the ubiquitin-proteasome system. Biochim Biophys Acta. 2015;1849(10):1289-97.

27. Kim JH, Dhanasekaran SM, Mehra R, Tomlins SA, Gu W, Yu J, Kumar-Sinha C, Cao X, Dash A, Wang L, et al. Integrative analysis of genomic aberrations associated with prostate cancer progression. Cancer Res. 2007;67(17):8229-39.

28. Bindra RS, Glazer PM. Repression of RAD51 gene expression by E2F4/p130 complexes in hypoxia. Oncogene. 2007;26(14):2048-57.

29. Kim TM, Ko JH, Hu L, Kim SA, Bishop AJ, Vijg J, Montagna C, Hasty P. RAD51 mutants cause replication defects and chromosomal instability. Mol Cell Biol. 2012;32(18):3663-80.

30. Nakamura K, Okamoto A, Katou Y, Yadani C, Shitanda T, Kaweeteerawat C, Takahashi TS, Itoh T, Shirahige K, Masukata H, et al. Rad51 suppresses gross chromosomal rearrangement at centromere in Schizosaccharomyces pombe. EMBO J. 2008;27(22):3036-46.

31. Stumm L, Burkhardt L, Steurer S, Simon R, Adam M, Becker A, Sauter G, Minner S, Schlomm T, Sirma H, et al. Strong expression of the neuronal transcription factor FOXP2 is linked to an increased risk of early PSA recurrence in ERG fusion-negative cancers. J Clin Pathol. 2013;66(7):563-8.

32. Grupp K, Boumesli R, Tsourlakis MC, Koop C, Wilczak W, Adam M, Sauter G, Simon R, Izbicki JR, Graefen M, et al. The prognostic impact of high Nijmegen breakage syndrome (NBS1) gene expression in ERG-negative prostate cancers lacking PTEN deletion is driven by KPNA2 expression. Int J Cancer. 2014;135(6):1399-407.

33. Grupp K, Jedrzejewska K, Tsourlakis MC, Koop C, Wilczak W, Adam M, Quaas A, Sauter G, Simon R, Izbicki JR, et al. High mitochondria content is associated with prostate cancer disease progression. Mol Cancer. 2013;12(1):145.

34. Burdelski C, Bujupi E, Tsourlakis MC, Hube-Magg C, Kluth M, Melling N, Lebok P, Minner S, Koop C, Graefen M, et al. Loss of SOX9 expression is associated with PSA recurrence in ERG-positive and PTEN deleted prostate cancers. PLoS One. 2015;10(6):e0128525. 
35. Cuzick J, Swanson GP, Fisher G, Brothman AR, Berney DM, Reid JE, Mesher D, Speights VO, Stankiewicz E, Foster CS, et al. Prognostic value of an RNA expression signature derived from cell cycle proliferation genes in patients with prostate cancer: a retrospective study. Lancet Oncol. 2011:12(3):245-55

36. Knezevic D, Goddard AD, Natraj N, Cherbavaz DB, Clark-Langone KM, Snable J, Watson D, Falzarano SM, Magi-Galluzzi C, Klein EA, et al. Analytical. validation of the Oncotype DX prostate cancer assay - a clinical RT-PCR assay optimized for prostate needle biopsies. BMC Genomics. 2013;14:690.

37. Sauter G, Steurer S, Clauditz TS, Krech T, Wittmer C, Lutz F, Lennartz M, Janssen T, Hakimi N, Simon R, et al. Clinical utility of quantitative Gleason grading in prostate biopsies and prostatectomy specimens. Eur Urol. 2016; 69(4):592-8.

Submit your next manuscript to BioMed Central and we will help you at every step:

- We accept pre-submission inquiries

- Our selector tool helps you to find the most relevant journal

- We provide round the clock customer support

- Convenient online submission

- Thorough peer review

- Inclusion in PubMed and all major indexing services

- Maximum visibility for your research

Submit your manuscript at www.biomedcentral.com/submit 